Pediat. Res. 6: 713-719 (1972)

Amino acid neonate

intestine transport, amino acid

\title{
Amino Acid Transport Pathways in the Small Intestine of the Neonatal Rat
}

\author{
J. F. Fitzgerald ${ }^{[43]}$, S. Reiser, and P. A. Christiansen \\ Departments of Pediatrics, Medicine, and Biochemistry, and Gastrointestinal Research Laboratory, Indiana University \\ School of Medicine and Veterans Administration Hospital, Indianapolis, Indiana, USA
}

\begin{abstract}
Extract
The activity of amino acid transport pathways in the small intestine of the 2-day-old rat was investigated. Transport was determined by measuring the uptake of $1 \mathrm{~mm}$ concentrations of various amino acids by intestinal segments after a 5- or 10-min incubation and it was expressed as intracellular accumulation.

The neutral amino acid transport pathway was well developed with intracellular accumulation values for leucine, isoleucine, valine, methionine, tryptophan, phenylalanine, tyrosine, and alanine ranging from 3.9-5.6 mm/5 min. The intracellular accumulation of the hydroxy-containing neutral amino acids threonine (essential) and serine (nonessential) were $2.7 \mathrm{~mm} / 5 \mathrm{~min}$, a value significantly lower than those of the other neutral amino acids. The accumulation of histidine was also well below the level for the other neutral amino acids $(1.9 \mathrm{~mm} / 5 \mathrm{~min})$. The basic amino acid transport pathway was also operational with accumulation values for lysine, arginine and ornithine ranging from 1.7-2.0 mm/5 min. Accumulation of the essential amino acid lysine was not statistically different from that of nonessential ornithine. Accumulation of aspartic and glutamic acid was only $0.24-0.28 \mathrm{~mm} / 5 \mathrm{~min}$ indicating a very low activity of the acidic amino acid transport pathway. Accumulation of sarcosine and betaine was about $0.5 \mathrm{~mm} / 5 \mathrm{~min}$, which indicates a low activity for the imino acid-glycine pathway. The presence of $1 \mathrm{~mm}$ alanine significantly $(P<0.01)$ increased the accumulation of lysine by $28.5 \%$, which suggests the presence of an exchange transport system.

These results show that by operation of the neutral and basic amino acid transport systems, the neonatal rat can effectively absorb all the essential amino acids; however, accumulation of individual amino acids appears to be governed by structural rather than nutritional considerations.
\end{abstract}

\section{Speculation}

The data presented demonstrate the differential ability of the neonatal rat to absorb various amino acids. This finding is of potential importance in the formulation and evaluation of synthetic protein diets.

\section{Introduction}

The quality and quantity of dietary protein which would result in optimal growth and development of infants at a reasonable cost is a subject that has been discussed by nutritionists for several decades. Such discussion stimulated investigation of intestinal transport at, or shortly after birth $[4-6,13,15,30]$.

A recent article by the authors [15] characterized the 
postnatal developmental patterns of transport of certain amino acids and sugars. The transport of two sugars, thought to share a common carrier system, and of three amino acids, thought to have separate carrier systems, was found to be maximal immediately after birth. The three amino acids showed distinct variation in their developmental transport patterns whereas the sugars had similar patterns. A study of the kinetics of the accelerated transport of valine by 2-day-old rat intestine [30] suggested the presence of more transport sites rather than more efficient binding by the carrier. These studies demonstrate the ability of intestine from the newborn rat to transport rapidly both amino acids and sugars.

The availability of formulas containing various combinations of amino acids suggested the importance of defining the different pathways of amino acid transport that are present immediately after birth. The purpose of this investigation was to characterize the transport pathways mediating amino acid transport in the newborn rat with particular emphasis on structural and nutritional considerations.

\section{Methods and Materials}

Two-day-old Wistar strain rats of both sexes were used as a source of intestinal segments. Rats were killed by decapitation; the small intestine was quickly removed and placed in oxygenated isotonic saline. The intestine was then split longitudinally while it was immersed in the saline. Intestinal segments were essentially free of luminal contents and usually weighed $100-300 \mathrm{mg}$. The segments were then placed in $5 \mathrm{ml}$ oxygenated Krebs-Tris buffer ( $\mathrm{pH} 7.4$ ) that contained $118 \mathrm{~mm} \mathrm{NaCl}, 25 \mathrm{~mm}$ Tris- $\mathrm{HCl}, 4.7 \mathrm{~mm} \mathrm{KCl}, 2.5 \mathrm{~mm}$ $\mathrm{CaCl}_{2}, \quad 1.2 \mathrm{~mm} \quad \mathrm{MgSO}_{4}, \quad 1.2 \mathrm{~mm} \quad \mathrm{KH}_{2} \mathrm{PO}_{4}$ and $8,000-12,000$ counts/min per milliliter of ${ }^{14} \mathrm{C}$-labeled and nonradioactive amino acid to the desired final concentration. In addition, 10,000-15,000 counts/min per milliliter of methoxy- ${ }^{3} \mathrm{H}$-inulin were added to the medium to measure the extracellular space of the tissue [32]. Segments were incubated at $37^{\circ}$ for the indicated time periods, after which they were washed quickly in saline, blotted and weighed. The segments then were homogenized in four times their weight of $5 \%$ trichloroacetic acid. The homogenate was centrifuged and aliquots of the supernatant were counted in a liquid scintillation spectrometer [38] in a system that contained xylene-dioxane-ethanol $(5: 5: 3)$, naphthalene (40 g/liter), 2,5-diphenyloxazole ( $5 \mathrm{~g} /$ liter), and 1,4-bis-2-(5-phenyloxazolyl)-benzene $\quad(100 \mathrm{mg} /$ liter $)$.
The spectrometer was adjusted to permit $60 \%{ }^{14} \mathrm{C}$ efficiency, $22 \%{ }^{3} \mathrm{H}$ efficiency, less than $0.01 \%{ }^{3} \mathrm{H}$ efficiency on the ${ }^{14} \mathrm{C}$ channel, and $10 \%{ }^{14} \mathrm{C}$ efficiency on the ${ }^{3} \mathrm{H}$ channel. Amino acid transport is expressed as intracellular accumulation which is defined as the millimolar concentration of the amino acid in the cellular water after a given incubation period. This parameter was calculated on the basis of a modification of a formula used by Crane and Mandelstam [12] which now takes the following form: $\mathrm{mm}$ (cellular water) $=(\mathrm{mm}$ homogenate supernatant $x$ homogenate volume) - (extracellular space $\times$ tissue wet weight $\times 0.8 \times \mathrm{mm}$ medium $) /(1$-extracellular space $\times$ tissue wet weight $\times$ 0.8 ). This conversion was based on the assumption that the water content of the tissue is approximately $80 \%$ of the tissue wet weight [36]. The counting rate of each individual experiment was mathematically treated so that 10,000 counts $/ \mathrm{min}$ per $\mathrm{ml}$ were equivalent to the initial concentration of the amino acid. This permitted conversion of counts to $\mu$ moles amino acid from identical experiments having somewhat different initial counting rates.

The source and specific activity of the radioactive compounds used in this study were: carboxyl ${ }^{14} \mathrm{C}$-cycloleucine $(54 \mathrm{mCi} / \mathrm{mmole})$, methylene- ${ }^{14} \mathrm{C}$-L-tryptophan (56.5 mCi $/ \mathrm{mmole})$, and $1^{-14} \mathrm{C}$-sarcosine $(12.9 \mathrm{mCi} /$ mmole) $[39] ;{ }^{14} \mathrm{C}$ uniformly labeled L-asparagine (218 $\mathrm{mCi} /$ mmole), L-aspartic acid $(229 \mathrm{mCi} / \mathrm{mmole})$, L-arginine monohydrochloride ( $324 \mathrm{mCi} / \mathrm{mmole})$, L-glutamic acid (260 mCi/mmole), glycine (109 mCi/mmole), L-isoleucine (312 mCi/mmole), L-leucine ( $344 \mathrm{mCi} / \mathrm{mmole})$, L-lysine monohydrochloride (312 $\mathrm{mCi} / \mathrm{mmole})$, L-phenylalanine $(477 \mathrm{mCi} / \mathrm{mmole})$, L-proline $(265 \mathrm{mCi} /$ mmole), L-serine (162 $\mathrm{mCi} / \mathrm{mmole})$, L-threonine (208 $\mathrm{mCi} / \mathrm{mmole})$, L-tyrosine $(513 \mathrm{mCi} / \mathrm{mmole})$ and $\mathrm{L}$-valine (260 mCi/mmole) [39]; $\alpha-3{ }^{-14} \mathrm{C}$-aminoisobutyric acid (2.72 $\mathrm{mCi} / \mathrm{mmole}), \quad \gamma^{-1}{ }^{14} \mathrm{C}$-aminobutyric acid (1.64 $\mathrm{mCi} / \mathrm{mmole}), \beta-1-{ }^{14} \mathrm{C}$-alanine $(4.75 \mathrm{mCi} / \mathrm{mole})$, methyl${ }^{14} \mathrm{C}$-betaine hydrochloride $(2.6 \mathrm{mCi} / \mathrm{mmole})$, methoxy- ${ }^{3} \mathrm{H}$-inulin (672 $\left.\mathrm{mCi} / \mathrm{mmole}\right)$, and ${ }^{1-14} \mathrm{C}$-D-leucine (24.6 mCi/mmole) [40]; and ${ }^{14} \mathrm{C}$ uniformly labeled L-alanine (137 $\mathrm{mCi} / \mathrm{mmole})$, L-histidine ( $256 \mathrm{mCi} / \mathrm{mmole})$, L-methionine $(222 \mathrm{mCi} / \mathrm{mmole})$ and L-ornithine (204 $\mathrm{mCi} / \mathrm{mmole}$ ) [40].

\section{Results}

Table I presents the intracellular accumulation of various neutral amino acids after 5 -min incubation. Since accumulation of neutral amino acids by the small intestine was previously shown to be a linear function of 
time through the first $5 \mathrm{~min}$ of incubation [27, 28], these accumulations are assumed to represent initial velocity. The neutral amino acid transport pathway was well developed in 2-day-old rats, and accumulation values were generally in the 3.9-5.6 range. In agreement with results previously obtained by using valine $[15,30]$, it was found that accumulation of L-leucine, isoleucine, methionine, tryptophan, phenylalanine and alanine by 2-day-old rats was at least twice as high as accumulation of neutral amino acids by intestinal segments from adult rats. Accumulation of histidine was less than one-half that of the other neutral amino acids. Accumulation of the hydroxy-containing aliphatic amino acids threonine (essential) and serine (nonessential) was identical but also well below the range observed for most of the neutral amino acids. Accumulation of $\mathrm{D}$-leucine was not found to be concentrative.

The 2-day-old rats were also able to accumulate actively the basic amino acids lysine, arginine and ornithine (Table II), but at rates much lower than those observed for most of the neutral amino acids. These values are assumed to represent initial velocities, since previous studies have shown that the intracellular ac-

Table I. Intracellular accumulation of neutral $\alpha$-amino acids ${ }^{1}$

\begin{tabular}{lc}
\hline \multicolumn{1}{c}{ Amino acid, 1 mM } & Intracellular accumulation, $\mathrm{mm} / 5 \mathrm{~min}$ \\
\hline L-Leucine (13) & $5.00 \pm 0.27$ \\
L-Isoleucine (13) & $4.54 \pm 0.26$ \\
L-Valine (14) & $5.41 \pm 0.18$ \\
L-Methionine (12) & $4.14 \pm 0.31$ \\
L-Tryptophan (12) & $3.97 \pm 0.17$ \\
L-Phenylalanine (12) & $4.44 \pm 0.26$ \\
L-Tyrosine (13) & $5.04 \pm 0.38$ \\
L-Histidine HCl (12) & $1.87 \pm 0.13$ \\
L-Alanine (13) & $3.90 \pm 0.28$ \\
L-Threonine (12) & $2.65 \pm 0.19$ \\
L-Serine (11) & $2.66 \pm 0.17$ \\
D-Leucine (11) & $1.06 \pm 0.05$ \\
\hline
\end{tabular}

${ }^{1}$ Intestinal segments were incubated for $5 \mathrm{~min}$ at $37^{\circ}$ in a Krebs-Tris medium that contained the indicated neutral amino acid. Each value represents the mean \pm one SEM from the number of experiments given in parentheses.

Table II. Intracellular accumulation of basic amino acids ${ }^{1}$

\begin{tabular}{cc}
\hline \multicolumn{1}{c}{ Amino-acid, 1 mM } & Intracellular accumulation, $\mathrm{mm} / 5 \mathrm{~min}$ \\
\hline L-Lysine HCl (16) & $1.92 \pm 0.19$ \\
L-Arginine HCl (14) & $1.74 \pm 0.11$ \\
L-Ornithine HCl (11) & $1.98 \pm 0.12$ \\
\hline
\end{tabular}

1 Except for the substitution of basic amino acids, the methods used in obtaining and expressing the results are the same as for Table I.
Table III. Intracellular accumulation of acidic amino acids and asparagine ${ }^{1}$

\begin{tabular}{lc}
\hline \multicolumn{1}{c}{ Amino acid, 1 mM } & $\begin{array}{c}\text { Intracellutar } \\
\text { accumulation, } \\
\text { mM/5 min }\end{array}$ \\
\hline L-Glutamic acid (mono $\mathrm{Na}^{+}$salt) (10) & $0.24 \pm 0.02$ \\
L-Aspartic acid (mono $\mathrm{K}^{+}$salt) (9) & $0.28 \pm 0.06$ \\
L-Asparagine (10) & $2.88 \pm 0.29$ \\
\hline
\end{tabular}

${ }^{1}$ Except for the substitution of acidic amino acids and asparagine, the methods used in obtaining and expressing the results are the same as for Table I.

Table $I V$. Intracellular accumulation of neutral amino acids transported by the imino acid-glycine pathway ${ }^{1}$

\begin{tabular}{lc}
\hline \multicolumn{1}{c}{ Amino acid, 1 mM } & Intracellular accumulation, $\mathrm{mm} / 5 \mathrm{~min}$ \\
\hline Glycine (12) & $1.11 \pm 0.18$ \\
L-Proline (13) & $1.44 \pm 0.13$ \\
Betaine HCl (12) & $0.48 \pm 0.10$ \\
Sarcosine HCl (13) & $0.46 \pm 0.03$
\end{tabular}

1 Except for the substitution of the indicated amino and imino acids, the methods used in obtaining and expressing the results are the same as for Table 1 .

cumulation of lysine after $5 \mathrm{~min}$ is a linear function of time [26]. Since the apparent $\mathrm{K}_{\mathrm{m}}$ 's of lysine and arginine for the basic amino acid carrier are at least as low as the corresponding $\mathrm{K}_{\mathrm{m}}$ 's of the neutral amino acids for their carrier [14, 18, 26, 30], this lowered accumulation rate could not be attributed to differences in affinity for the carriers. On the basis of unpaired difference $t$-tests, the accumulation of the nonessential amino acid ornithine was found to be identical to that of the essential amino acid lysine but statistically greater than that of the essential amino acid arginine $(P<0.01)$.

In agreement with findings obtained with segments from adult rats [14] and Ehrlich ascites cells [17], the rates of accumulation of glutamic acid and aspartic acid by the segments from 2-day-old rats were very low (Table III). The amide of aspartic acid, asparagine, had a rate of accumulation about 10 times greater than that of the free acid.

The existence of two transport systems for neutral amino acids in mammalian small intestine is generally accepted [3, 22, 34]. One system has high affinity for neutral amino acids with lipophilic side chains, such as those listed in Table I. The second system has more affinity for imino acids, proline, glycine, and the $\mathrm{N}$ substituted glycine derivatives such as betaine and sarcosine [3]. Proline and glycine probably have affinities for both neutral amino acid transport pathways [22]. Table IV shows the intracellular accumulation of 
Table $V$. Intracellular accumulation of $\beta, \gamma$ and nonmetabolized neutral amino acids ${ }^{1}$

\begin{tabular}{lc}
\hline \multicolumn{1}{c}{ Amino acid, 1 mM } & $\begin{array}{c}\text { Intracellular accumulation, } \\
\mathrm{mM} / 5 \mathrm{~min}\end{array}$ \\
\hline Cycloleucine (14) & $2.28 \pm 0.13$ \\
$\alpha$-Aminoisobutyric acid (15) & $0.30 \pm 0.03$ \\
$\beta$-Alanine (11) & $0.23 \pm 0.04$ \\
$\gamma$-Aminobutyric acid (8) & $0.15 \pm 0.02$ \\
\hline
\end{tabular}

${ }^{1}$ Except for the substitution of the indicated $\beta, \gamma$, and nonmetabolized amino acids, the methods used in obtaining and expressing the results are the same as for Table $\mathrm{X}$.

some amino acids utilizing the imino acid-glycine pathway. Although their accumulations were appreciably lower than those of the neutral amino acids shown in Table $\mathrm{I}$, accumulations of the amino acids that used both neutral amino acid pathways (i.e., glycine and proline) were significantly greater $(P<0.001)$ than the very slow accumulations of the amino acids that used only the imino acid-glycine pathway (i.e., betaine and sarcosine).

Use of the nonmetabolized amino acids cycloleucine and $\alpha$-aminoisobutyric acid for the study of various aspects of intestinal transport are well documented [1, $10,35]$. Table $\mathrm{V}$ shows that the accumulation of the cycloleucine was concentrative and reached values that were about half of those attained by most of the neutral amino acids listed in Table $\mathrm{I}$. In contrast, the rate of accumulation of $\alpha$-aminoisobutyric acid was only about one-eighth that of cycloleucine. Table $\mathrm{V}$ also indicates that the presence of the amino group at the $\alpha$ position appears to be a prerequisite for active neutral amino acid accumulation in 2-day-old intestine. A similar requirement has been shown to exist in adult hamster intestine [18].

Numerous studies on the stimulation of basic amino acid transport by various neutral amino acids in the intact adult mammalian intestine have been previously reported $[23,24,26,31]$. This stimulation has recently been attributed to an exchange transport system [29]. In order to determine whether the exchange transport system is already present in intestine from 2-day-old rats, lysine accumulation was determined in the absence and presence of various amino acids (Table VI). Lysine accumulation in the presence of alanine or leucine was significantly stimulated, by 25.8 and $11.9 \%$ respectively. Both alanine and leucine have been shown to stimulate lysine transport in adult intestine [26, 29]. Valine, which did not stimulate lysine transport in adult intestine [26, 29], did not stimulate lysine transport in intestine from 2-day-old rats. Arginine caused a significant inhibition of lysine accumulation, as would be expected on the basis of their transport by the basic amino acid pathway [16].

\section{Discussion}

The active accumulation of amino acids by small intestine from 2-day-old rats appears to be mediated by two major transport systems. The more active of these transport systems has the highest affinity for neutral L-amino acids with lipophilic side chains. Introduction of hydrophilic groups into the side chain results in a decrease of affinity for this pathway as is illustrated by the significant decrease in the accumulation of serine as compared with alanine. The second transport pathway has affinity for the basic amino acids. Amino acid transport pathways having similar affinitives have been extensively described in adult mammalian intestine. By the operation of these two transport systems, the neonatal rat can effectively absorb all the dietary amino acids classified as essential. Accumulation of these amino acids has been studied at a concentration of $1 \mathrm{~mm}$. Since we have made no effort to study the kinetics of the accumulation of each of these amino acids, it is not possible to infer that the maximal capacity of accumulation of these amino acids would correspond to the accumulation at $1 \mathrm{~mm}$.

Despite the nutritional importance of the operation of these two transport pathways, intracellular accumu-

Table VI. Effect of various amino acids on intracellular accumulation of $1 \mathrm{~mm}$ lysine ${ }^{1}$

\begin{tabular}{lccc}
\hline \multirow{2}{*}{ Amino acid } & \multicolumn{3}{c}{ Intracellular accumulation of lysine } \\
& m. $/ 10$ min & \% control ${ }^{2}$ & $P^{3}$ \\
\hline None (17) & $2.41 \pm 0.18$ & & \\
Alanine (17) & $3.03 \pm 0.16$ & 125.8 & $<0.01$ \\
Arginine (17) & $1.04 \pm 0.05$ & 43.1 & $<0.001$ \\
None (20) & $2.50 \pm 0.15$ & & \\
Leucine (20) & $2.79 \pm 0.16$ & 111.9 & $<0.05$ \\
Valine (20) & $2.28 \pm 0.13$ & 91.5 & \\
\hline
\end{tabular}

1 Intestinal segments were incubated for $10 \mathrm{~min}$ at $37^{\circ}$ in a Krebs-Tris medium that contained $1 \mathrm{~mm}$ L-lysine without or with $1 \mathrm{~mm}$ of the indicated amino acid. Each value represents the mean \pm 1 sEM from the number of individual experiments, as indicated in the parentheses.

${ }^{2}$ Per cent of control value equals average intracellular accumulation of lysine in the presence of the added amino acid divided by that in absence of added amino acid.

${ }^{3}$ Probability values were obtained by paired-difference $t$ test. $P \leq 0.05$ was considered significant. 
lation of amino acids appears to be governed by structural rather than nutritional considerations. For example, the essential neutral amino acids phenylalanine and threonine and the essential basic amino acid lysine were not accumulated more rapidly than their structurally similar nonessential amino acid counterparts tyrosine, serine, and ornithine. In contrast, modifications in the structure of the neutral amino acid profoundly influenced the rate of accumulation. Lowering of neutral amino acid accumulation by introduction of the hydrophilic hydroxy group has already been mentioned. Replacement of a hydrogen in a methyl group of alanine with the negatively charged hydrophilic carboxylate group to form aspartic acid virtually abolishes amino acid accumulation. Removal of the net negative charge and most of the hydrophilic properties of the side chain of aspartic acid by formation of the amide asparagine results in reappearance of active accumulation, presumably by the neutral amino acid pathway [14]. The slow accumulation of histidine as compared with other neutral amino acids that was noted in this study has also been reported for adult rat intestine [14] and this also seems to be due to structural considerations. The finding that a variety of epithelial cells appear to have a low isoelectric pH (i.e., $\mathrm{pH} 3.5$ or lower) $[2,20,37]$ raises the possibility that the $\mathrm{pH}$ microclimate in the region of histidine uptake may be low enough to favor the formation of the positively charged imidizolium cation form of histidine [9]. This possibility is supported by the fonding that the influx of lysine and histidine across the intestinal brush border are mutually inhibitory [9]. Predominance of the imidizolium cation form would lower the affinity of histidine for the neutral amino acid system [25], or perhaps even classify histidine partially as a basic amino acid.

The neutral amino acid transport pathway with absolute specificity for amino acids such as betaine and sarcosine [22] does not appear too well developed in intestine from 2-day-old rats. This conclusion is based on the very slow accumulation of sarcosine as compared with that of glycine and proline. Munck [22] has shown that the rates of transport of these three amino acids are comparable in adult rat intestine. Accumulation of proline and glycine by 2 -day-old rats is attributed to their low affinity for the primary neutral amino acid transport system. Extremely slow accumulation of $\alpha$-aminoisobutyric acid in the 2-day-old rat indicates that this nonmetabolized amino acid is transported by the imino acid-glycine pathway, as was first suggested by Akedo and Christensen [1]. Baker and George [3] have recently shown that the pattern of betaine and $\alpha$-aminoisobutyric acid uptake along adult rat intestine is very similar, which further indicates that $\alpha$-aminoisobutyric acid is transported by the same pathway as is used by betaine and sarcosine. The slow accumulation of $\alpha$-aminoisobutyric acid can not be explained by loss of affinity for the primary neutral amino acid transport system because of the lack of $\alpha$-hydrogen, since cycloleucine was actively accumulated.

The presence in 2-day-old intestine of the transport systems responsible for stimulation of lysine accumulation by certain neutral amino acids [30] may be of nutritional significance. Accumulation of the basic amino acids by neonatal rats was slow compared with that of the neutral amino acids. Since both lysine and arginine are nutritionally essential, it is interesting to speculate that this transport pathway increased the accumulation of these basic amino acids to levels required to meet the needs of the rapid rate of neonatal protein biosynthesis.

Recent studies have indicated that the intestinal absorption of amino acids from dipeptides occurs more rapidly than from the free amino acid $[11,19]$ and is apparently mediated by an independent transport system $[8,33]$. Since low molecular weight peptides account for most of the nitrogenous material in the intestinal lumen during digestion of a protein meal [7, 21], this transport system may represent a potentially important pathway for mediating amino acid absorption from dietary protein.

\section{Summary}

The activity of amino acid transport pathways in the small intestine of the 2-day-old rat was determined by measuring the intracellular accumulation of $1 \mathrm{~mm}$ concentrations of various amino acids by intestinal segments after 5 or $10 \mathrm{~min}$.

The amino acid transport pathways mediating the accumulation of neutral amino acids with lipophilic side chains and that of basic amino acids showed the greatest activity. The pathways mediating the transport of the acidic amino acids, imino acids, and N-substituted amino acids showed minor activity. The presence of an exchange transport system was suggested by the ability of alanine and leucine to stimulate lysine accumulation.

These results indicate that, by operation of the neu- 
tral and basic amino acid transport systems and possibly the exchange transport system, the neonatal rat can effectively absorb all the essential amino acids; however, accumulation of individual amino acids appears to be governed by structural rather than nutritional considerations.

\section{References and Notes}

1. Akedo, H., and Christensen, H. N.: Transfer of amino acids across the intestine: a new model amino acid. J. Biol. Chem., 237: 113 (1962).

2. Ambrose, E. J., James, A. M., nNd Lowick, J. H. B.: Differences between the electrical charge carried by normal and homologous tumor cells. Nature, 177: 576 (1952).

3. BAKer, R. D., AND George, M. J.: Patterns of neutral amino acid uptake along rat small intestine. Biochim. Biophys. Acta, 225: 315 (1971).

4. Batt, E. R., AND SChachter, D.: Developmental pattern of some intestinal transport mechanisms in newborn rats and mice. Amer. J. Physiol., 216: 1064 (1969).

5. Bogner, P. H., And Haines, $X$. A.: Functional development of active sugar transport in the chick intestine. Amer. J. Physiol., 207: 37 (1964).

6. Butr, J. H., JR., And Wilson, T. H.: Development of sugar and amino acid transport by intestine and yolk sac of the guinea pig. Amer. J. Physiol., 215: 1468 (1968).

7. Chen, M. L., Rogers, Q. R., And Harper, A. E.: Observations on protein digestion in vivo. IV. Further observations on the gastrointestinal contents of rats fed different dietary proteins. J. Nutr., 76: 235 (1962).

8. Cheng, B., Narab, F., Lis, M. T., Miller, T. N., and MatTHEws, D. M.: Mechanisms of dipeptide uptake by rat small intestine in vitro. Clin. Sci., 40: 247 (1971).

9. Chezz, R. A., Strecker, C. K., Curran, P. F., and Schultz, S. G.: Histidine influx across brush border of rabbit ileum. Biochim. Biophys. Acta, 233: 222 (1971).

10. Christensen, H. N., Feldman, B. H., and Hastings, A. B.: Concentrative and reversible character of intestinal amino acid transport. Amer. J. Physiol., 205: 255 (1963).

11. Craft, I. L., Geddes, D., Hyde, C. W., Wise, I. J., and MaxTHEws, D. M.: Absorption and malabsorption of glycine and glycine peptides in man. Gut, 9: 425 (1968).

12. Crane, R. K., And Mandelstam, P.: The active transport of sugars by various preparations of hamster intestine. Biochim. Biophys. Acta, 45: 460 (1960).

13. Deren, J. J., Strauss, E. W., and Wrlson, T. H.: The development of structure and transport systems of the fetal rabbit intestine. Develop. Biol., 13: 370 (1965).

14. Finch, L. R., AND HrRd, F. J. R.: The uptake of amino acids by isolated segments of rat intestine. II. A survey of affinity for uptake from rates of uptake and competition for uptake. Biochim. Biophys. Acta, 43: 278 (1960).

15. Fitzgerald, J. F., Rerser, S., and Christiansen, P. A.: Developmental pattern of sugar and amino acid transport in the postnatal rat small intestine. Pediat. Res., 5: 698 (1971).

16. Hagihira, H., Lin, E. C. C., Samiy, A. H., and Wilson, T. H.: Active transport of lysine, ornithine, arginine and cystine by the intestine. Biochim. Biophys. Res. Comm., 4: 478 (1961).
17. Heinz, E., Loewe, U., Despopoulos, A., and Pfeiffer, B.: Transport and metabolism of glutamate in Ehrlich ascites carcinoma cells. Biochem. Z., 340: 487 (1964).

18. Lin, E. C. C., Hagihira, H., and Wilson, T. H.: Specificity of the transport system for neutral amino acids in the hamster intestine. Amer. J. Physiol., 202: 919 (1962).

19. Lis, M. T., Crampton, R. F., and Matrhews, D. M.: Rates of absorption of a dipeptide and the equivalent free amino acid in various mammalian species. Biochim. Biophys. Acta, 233: 453 (1971).

20. Lrpman, K. M., Dodelson, R., and Hays, R. M.: The surface charge of isolated toad bladder epithelial cells, mobility effect of $\mathrm{pH}$ and divalent ions. J. Gen. Physiol., 49: 50I (1966).

21. Mauer, G. E., And Nixon, E.: The net absorption of the amino acid constituents of a protein meal in normal and cystinuric subjects. Clin. Sci., 36: 463 (1969).

22. MUnck, B. G.: Amino acid transport by the small intestine of the rat. The existence and specificity of the transport mechanism of imino acids and its relation to the transport of glycine. Biochim. Biophys. Acta, 120: 97 (1966).

23. Munck, B. G.: Amino acid transport by the small intestine of the rat. On the counterflow phenomenon as a cause of the accelerating effect of leucine on the transintestinal transport of diamino acids. Biochim. Biophys. Acta, 120: 282 (1966).

24. Munck, B. G., AND Schultz, S. G.: Interactions between leucine and lysine transport in rabbit ileum. Biochim. Biophys. Acta, 183: 182 (1969).

25. Reiser, S., and Christiansen, P. A.: Intestinal transport of amino acids studied with L-valine. Amer. J. Physiol., 208: 914 (1965).

26. Reiser, S., and Christiansen, P. A.: A cross-inhibition of basic amino acid transport by neutral amino acids. Biochim. Biophys. Acta, 183: 611 (1969).

27. Reiser, S., and Christiansen, P. A.: Intestinal transport of amino acids as affected by sugars. Amer. J. Physiol., 216: 915 (I969).

28. Reiser, S., and Christiansen, P. A.: The properties of the preferential uptake of L-leucine by isolated intestinal epithelial cells. Biochim. Biophys. Acta, 255: 123 (1971).

29. Reiser, S., and Christransen, P. A.: Stimulation of basic amino acid uptake by certain neutral amino acids in isolated intestinal epithelial cells. Biochim. Biophys. Acta, 241: 102 (1971).

30. Reiser, S., Fitzgerald, J. F., and Christiansen, P. A.: Kinetics of the accelerated intestinal transport in 2-day-old rats. Biochim. Biophys. Acta, 203: 351 (1970).

31. Robinson, J. W. L., And Felber, J. P.: A survey of the effect of other amino acids on the absorption of L-arginine and L-lysine by the rat intestine. Gastroenterologia, 101: 330 (1964).

32. Rosenberg, L. E., Downing, S. T., and Segal, S.: The extracellular space estimation in rat kidney slices using $\mathrm{C}^{14}$ saccharides and phlorizin. Amer. J. Physiol., 202: 800 (1962).

33. Rubins, A., Freld, M., ANd Schwachman, H.: Intestinal transport of amino acid residues of dipeptides. I. Influx of the glycine residue of glycyl-L-proline across mucosal border. J. Biol. Chem., 246: 3542 (1971).

34. Saunders, S. J., and Isselbacher, K. J.: Intestinal absorption of amino acids. Gastroenterology, 50: 586 (1966). 
35. Schedl, H. P., Miller, D. L., Wrlson, H. D., ANd Flores, P.: $\alpha$-Aminoisobutyric acid transport and tissue concentration at various intestinal sites. Amer. J. Physiol., 216: I131 (I969).

36. Spencer, R. P., And Samiy, A. H.: Intestinal absorption of L-phenylalanine in vitro. Amer. J. Physiol., 200: 501 (1961).

37. VASSAR, P. S.: The electricial charge density of human tumor cell surfaces. Lab. Invest., 12: 1072 (1963).

38. Tri-Carb, Packard Instrument, Downers Grove, Ill.

39. Amersham/Searle Corporation, Des Plaines, IlI.
40. New England Nuclear Corporation, Boston, Mass.

41. The authors are indebted to Mrs. L. E. Ferdinandus for her technical assistance.

42. Supported by Riley Memorial Association project no. 71-4.

43. Requests for reprints should be addressed to: J. F. FitzGERALD, M.D., Department of Pediatrics, Section of Gastroenterology, Indiana University School of Medicinc, 1100 West Michigan Street, Indianapolis, Indiana 46202 (USA).

44. Accepted for publication May 2, 1972. 